\title{
1 Estimating daily full-coverage and high-accuracy 5-km ambient 2 particulate matters across China: considering their precursors and 3 chemical compositions
}

\author{
4 Yuan Wang ${ }^{1}$, Qiangqiang Yuan ${ }^{1,4,5}$, Tongwen $\mathrm{Li}^{2}$, Siyu $\operatorname{Tan}^{1}$, Liangpei Zhang ${ }^{3,5}$ \\ $5{ }^{1}$ School of Geodesy and Geomatics, Wuhan University, Wuhan, Hubei, 430079, China. \\ 6 2School of Geospatial Engineering and Science, Sun Yat-sen University, Zhuhai, Guangdong, 519082, China. \\ $7{ }^{3}$ The State Key Laboratory of Information Engineering in Surveying, Mapping and Remote Sensing, Wuhan University, \\ 8 Wuhan, Hubei, 430079, China. \\ $9{ }^{4}$ The Key Laboratory of Geospace Environment and Geodesy, Ministry of Education, Wuhan University, Wuhan, Hubei, \\ 10430079 , China. \\ $11{ }^{5}$ The Collaborative Innovation Center for Geospatial Technology, Wuhan, Hubei, 430079, China. \\ 12 Correspondence to: Qiangqiang Yuan (yqiang86@gmail.com)
}

13 Abstract. The ambient concentrations of particulate matters $\left(\mathrm{PM}_{2.5}\right.$ and $\left.\mathrm{PM}_{10}\right)$ are significant indicators for monitoring 14 the air quality relevant to living conditions. Most of the existing approaches for the estimation of $\mathrm{PM}_{2.5}$ and $\mathrm{PM}_{10}$

15 employed the remote sensing Aerosol Optical Depth (AOD) products as the main variate. Nevertheless, the coverage of 16 missing data is generally large in AOD products, which can cause inconvenience to the researchers. To efficiently address

17 this issue, our study explores a novel approach using the datasets of the precursors \& chemical compositions for $\mathrm{PM}_{2.5}$

18 and $\mathrm{PM}_{10}$ instead of AOD products. Specifically, the daily full-coverage ambient concentrations of $\mathrm{PM}_{2.5}$ and $\mathrm{PM}_{10}$ are

19 estimated at 5-km $\left(0.05^{\circ}\right)$ spatial girds across China based on Sentinel-5P and GEOS-FP. In this paper, the Light Gradient

20 Boosting Machine is exploited to train the estimation models, which will fully fuse the multi-source data. For comparison,

21 the Deep Blue AOD product from VIIRS is adopted in a similar framework as a baseline (AOD-based). The validation

22 results show that the ambient concentrations are well estimated through the proposed approach, with the sample-based

23 Cross-Validation $\mathrm{R}^{2} \mathrm{~s}$ and RMSEs of $0.93(0.9)$ and $8.982(17.604) \mu \mathrm{g} / \mathrm{m}^{3}$ for $\mathrm{PM}_{2.5}\left(\mathrm{PM}_{10}\right)$, respectively. Meanwhile, the

24 proposed approach achieves better performance than the AOD-based in different cases (e.g., overall and seasonal).

25 Compared to the related previous works over China, the estimation accuracy of our method is also satisfactory.

26 Furthermore, all the variates of the precursors \& chemical compositions for $\mathrm{PM}_{2.5}$ and $\mathrm{PM}_{10}$ positively contribute to the

27 estimation in the proposed approach, as expected. With regard to the mapping, the estimated results through the proposed

28 approach present consecutive spatial distribution and can exactly express the seasonal variations of $\mathrm{PM}_{2.5}$ and $\mathrm{PM}_{10}$. It is

29 concluded that the full-coverage estimated results in our study are conducive to the researches on $\mathrm{PM}_{2.5}$ and $\mathrm{PM}_{10}$ over

30 the regions where the AOD values are missing. 


\section{Introduction}

32 Particulate matters with aerodynamic equivalent diameters less than $2.5 \mu \mathrm{m}\left(\mathrm{PM}_{2.5}\right)$ and $10 \mu \mathrm{m}\left(\mathrm{PM}_{10}\right)$ have been 33 considered as major air pollutants for decades (Finlayson-Pitts et al., 1997; Hall et al., 1992; Lee, 1972), which can hazard 34 the environment and human health (Crippa et al., 2019; Liu et al., 2020; Ma et al., 2017; Venkataraman et al., 2018). The 35 ambient concentrations of $\mathrm{PM}_{2.5}$ and $\mathrm{PM}_{10}$ are strongly relevant to living conditions and required to be accurately 36 monitored. Generally, ground-based stations are recognized as the most direct and dependable approach to obtain the 37 ambient concentrations of $\mathrm{PM}_{2.5}$ and $\mathrm{PM}_{10}$ (Engel-Cox et al., 2013; Li et al., 2017a; Yang et al., 2020a, 2020b).

38 Nevertheless, the establishing of ground-based stations is costly, which causes difficulties in the implementation (Shen et 39 al., 2020). Meanwhile, the measurements from ground-based stations are only applicable in small regions and fail to 40 provide a global perspective ( $\mathrm{Li}$ et al., 2020). Hence, the approaches based on Chemical Transport Models (CTMs) (Van 41 Donkelaar et al., 2010; Wang et al., 2016; Weagle et al., 2018) or remote sensing satellites (Chen et al., 2018; Li et al., 42 2020; Stafoggia et al., 2019; Shtein et al., 2020; Wei et al., 2019; Yao et al., 2019; You et al., 2015) have been developed 43 to enlarge the spatial coverage of the $\mathrm{PM}_{2.5}$ and $\mathrm{PM}_{10}$ monitoring. Since the uncertainties of the emission inventories 44 adopted in CTMs could be large in some areas (Li et al., 2017b), the approaches based on remote sensing satellites usually 45 achieve better performance than those based on CTMs.

46

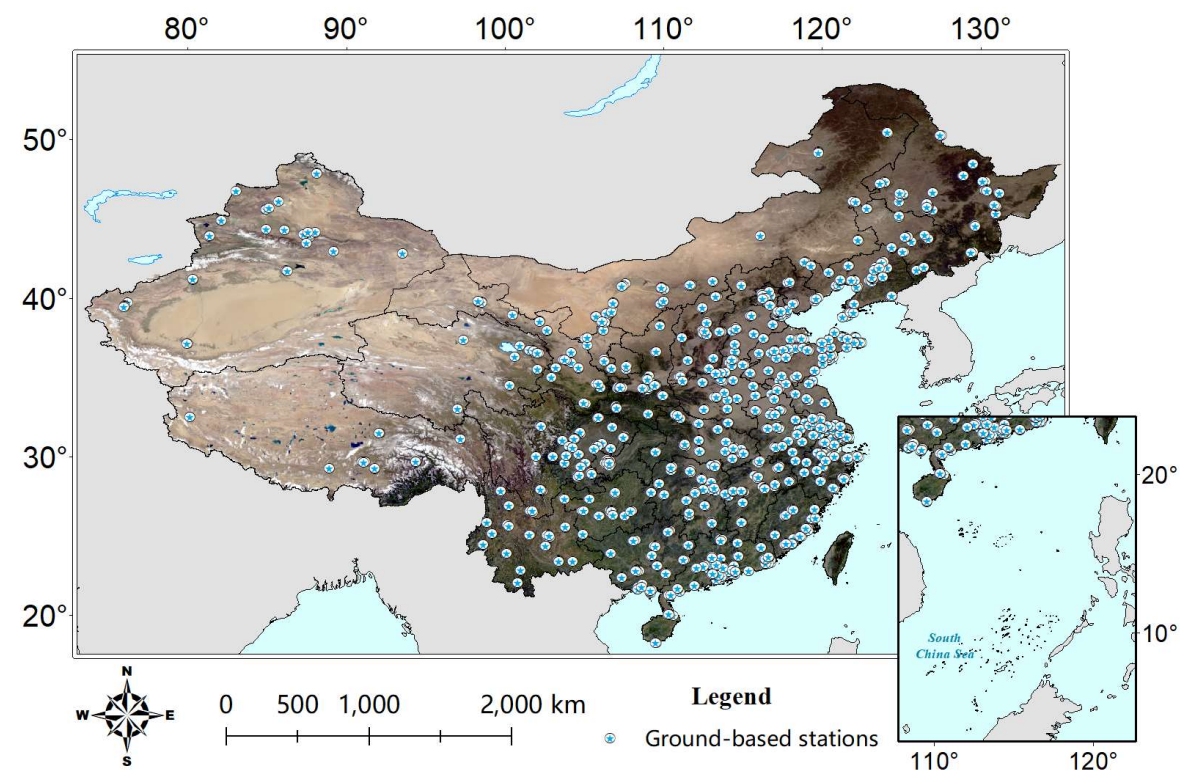

47 Figure 1. The spatial distribution of the ground-based stations over China. The base-map is the true color image of MODIS.

48 To date, numerous studies have researched on the estimation of the ambient particulate matters concentrations ( $\mathrm{PM}_{2.5}$ and $49 \mathrm{PM}_{10}$ ) using the observations from remote sensing satellites (Chen et al., 2018; Li et al., 2020; Stafoggia et al., 2019; 
50 Shtein et al., 2020; Wei et al., 2019; Yao et al., 2019; You et al., 2015). Thereinto, most of them will adopt a key

51 atmospheric parameter, i.e., Aerosol Optical Depth (AOD) (Wang et al., 2019a, 2019b), which presents high correlations

52 with the ambient concentrations of $\mathrm{PM}_{2.5}$ and $\mathrm{PM}_{10}$ (Guo et al., 2017; Li et al., 2019; Yang et al., 2019). For instance,

53 Chen et al. (2018) exploited the Random Forest (RF) to acquire the daily ambient concentrations of $\mathrm{PM}_{10}$ in China

54 employing the Deep Blue (DB) and Dark Target (DT) combined AOD products from the Moderate Resolution Imaging

55 Spectroradiometer (MODIS); Wei et al. (2019) proposed the Space-Time Random Forest model for the mapping of the

56 daily 1-km ambient concentrations of $\mathrm{PM}_{2.5}$ over China on the basis of the Multi-Angle Implementation of Atmospheric

57 Correction AOD product; Li et al. (2020) developed a brand-new method, i.e., the Geographically and Temporally

58 Weighted Neural Network, to obtain the daily ambient concentrations of $\mathrm{PM}_{2.5}$ across China, which is devised to fix the

59 spatiotemporal heterogeneous issues of the AOD-PM $\mathrm{PM}_{2.5}$ relationships. There is no doubt that these works have provided

60 wonderful results and made contributions to the atmospheric environment field. Nevertheless, the data is usually

61 unavailable in the AOD products from remote sensing satellites due to the influences from clouds, ice/snow, and

$62 \mathrm{arid} / \mathrm{semiarid}$ surface (only for DT-like AOD products) (Levy et al., 2013; Sayer et al., 2019). As a consequence, the

63 completeness of valid values in the estimated results $\left(\mathrm{PM}_{2.5}\right.$ and $\left.\mathrm{PM}_{10}\right)$ are also poor through the above-mentioned

64 approaches, which can result in inconvenience to the researchers. To remedy this deficiency, the algorithm of AOD

65 recovery is generally utilized as one of the preprocessing steps to fill the missing data in the AOD products. So far, these

66 algorithms achieve expected performance in local regions (Hua et al., 2019; Xiao et al., 2017) while still likely signify

67 considerable uncertainties for large scale. Hence, it is necessary to explore a novel approach for the estimation of $\mathrm{PM}_{2.5}$

68 and $\mathrm{PM}_{10}$ using other data sources instead of AOD products.

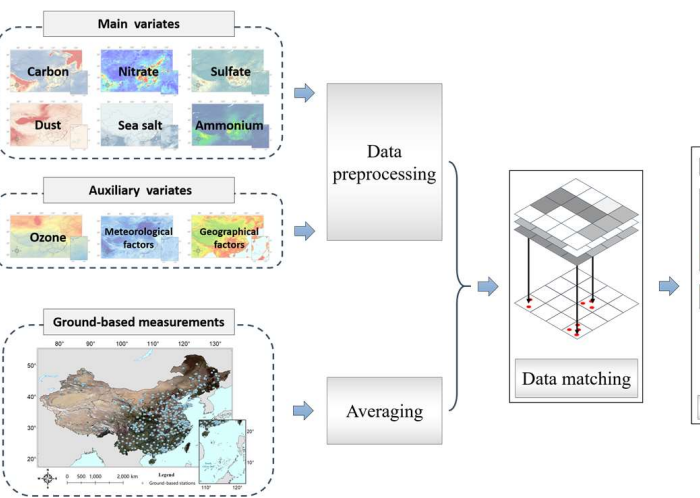

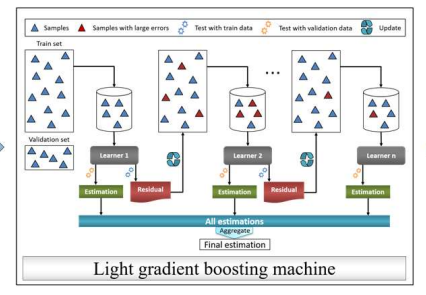

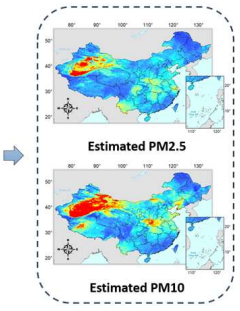

69

70 Figure 2. The flowchart of the proposed approach in our study. The models for the estimation of $\mathrm{PM}_{2.5}$ and $\mathrm{PM}_{10}$ are separately trained.

71 As is well-known, $\mathrm{PM}_{2.5}$ and $\mathrm{PM}_{10}$ consist of multiple chemical compositions (Dabek-Zlotorzynska et al., 2011; Tao et

72 al., 2017; Wang et al., 2019c), including sulfate, nitrate, black carbon, dust, etc. In the meantime, some chemical species 
73 are considered as the precursors for $\mathrm{PM}_{2.5}$ and $\mathrm{PM}_{10}$ (Baker et al., 2007; Heo et al., 2016; Tucker et al., 2000), such as

74 sulfur dioxide $\left(\mathrm{SO}_{2}\right)$ and nitrogen dioxide $\left(\mathrm{NO}_{2}\right)$. It is reasonable to estimate the ambient concentrations of $\mathrm{PM}_{2.5}$ and

$75 \mathrm{PM}_{10}$ based on these precursors \& chemical compositions. The Sentinel-5 Precursor (Sentinel-5P) satellite (Veefkind et

76 al., 2012) was launched on 13 October 2017, carrying the TROPOspheric Monitoring Instrument (TROPOMI) to generate

77 global high-coverage total/tropospheric vertically column of the precursors (e.g., $\mathrm{NO}_{2}$ ) for $\mathrm{PM}_{2.5}$ and $\mathrm{PM}_{10}$. Therefore, it

78 is feasible to adopt the atmospheric products of TROPOMI after the missing data recovery for small regions. However, it

79 would be insufficient for the estimation of the ambient particulate matters concentrations $\left(\mathrm{PM}_{2.5}\right.$ and $\left.\mathrm{PM}_{10}\right)$, only using

80 the datasets from TROPOMI as the major factors. The GEOS Forward Processing (GEOS-FP) (Lucchesi et al., 2013)

81 assimilated datasets from the Global Modeling and Assimilation Office (GMAO) can provide the seamless prior

82 information of the precursors \& chemical compositions for $\mathrm{PM}_{2.5}$ and $\mathrm{PM}_{10}$, which ought to be also introduced as the

83 major factors in our study.

84 The purpose of this study is to develop a novel approach to estimate the daily full-coverage $5-\mathrm{km}\left(0.05^{\circ}\right)$ ambient

85 concentrations of $\mathrm{PM}_{2.5}$ and $\mathrm{PM}_{10}$ using the datasets from TROPOMI and GEOS-FP. In our study, one of the ensemble

86 learning methods, i.e., the Light Gradient Boosting Machine (LGBM) (Ke et al., 2017), is applied for the estimation by

87 fusing the multi-source (TROPOMI, GEOS-FP, and ground-based stations) data. Meanwhile, the DB AOD product from

88 the Visible Infrared Imager Radiometer Sensor (VIIRS) (Hus et al., 2019) is employed in a similar framework as a baseline

89 (AOD-based) for comparison, which replaces the atmospheric products of TROPOMI and GEOS-FP. Comprehensive

90 experiments show that the approach proposed in our study well estimates the ambient particulate matters concentrations

91 and achieves better performance than the AOD-based, signified in both estimation accuracy and completeness of valid

92 values.

93 The remainder of this study is arranged as follows. Section 2 describes the study area and the datasets adopted in our

94 study. The methodology of the proposed approach is presented in Section 3. Section 4 provides the experiment results,

95 covering the model performance in different cases (e.g., overall and seasonal), the spatial distribution analyses, and some

96 discussions. At last, the conclusions are given in Section 5.

\section{Study area and datasets}

\section{$98 \quad 2.1$ Study area}

99 As the country with the largest population in the world ( $18 \%$ out of the world population by March 2019$)$, China is

100 regarded as the study area in this paper (shown in Figure 1). For more than ten years, air pollution issues (e.g., high-

101 polluted particulate matters) are rapidly emerging in China, which results from the acceleration of economic developments 
102 (Wang et al., 2019a). Thanks to the relevant regulations formulated by the government and the endeavors from social

103 various circles, the air quality has been greatly improved today, including the marked descent of particulate matters (Lin 104 et al., 2018; Ma et al., 2019). However, the pollutions of particulate matters are not optimistic over China by comparison 105 with a few developed countries in the world. Meanwhile, $\mathrm{PM}_{2.5}$ and $\mathrm{PM}_{10}$ are still deemed as the primary air pollutants of 106 urban areas in the eastern and northwestern China, respectively. It is necessary to develop an approach that can monitor $107 \mathrm{PM}_{2.5}$ and $\mathrm{PM}_{10}$ across China continuously and precisely.
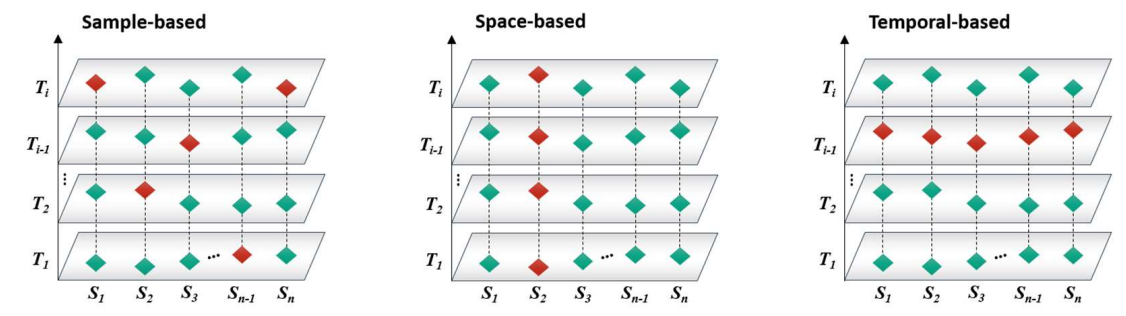

109 Figure 3. The schematic diagram of the validation methods in our study.

\section{2.2 Datasets}

111 In this study, the datasets from TROPOMI and GEOS-FP during June 1, 2018 to March 31, 2020 over China are deemed

112 as the main variates of the inputs in the proposed approach. Meanwhile, some other datasets are adopted as the auxiliary

113 variates of inputs to enlarge the applicability of the trained models, such as meteorological factors (e.g., planetary

114 boundary layer height and air temperature), Normalized Difference Vegetation Index (NDVI) (Beck et al., 2006), and

115 population density (Bai et al., 2018). In addition, the measurements from the China National Environmental Monitoring

116 Center (CNEMC) are considered as the ground truth-values, consisting of the hourly ambient concentrations of $\mathrm{PM}_{2.5}$ and

$117 \mathrm{PM}_{10}$. The descriptions of all datasets are provided as follows.

\section{2.2.1 Ground-based measurements}

119 In the study area, the hourly measurements of $\mathrm{PM}_{2.5}$ and $\mathrm{PM}_{10}$ during June 1, 2018 to March 31, 2020 are firstly allocated

120 from CNEMC, which can be obtained at http://106.37.208.233:20035/. The spatial distribution of ground-based stations

121 utilized in this study is demonstrated in Figure 1, using the marks of circles with pentacles inside. As illustrated, a total

122 of $\sim 1640$ ground-based sites (by March 2020) are established in the study area to monitor the pollution of $\mathrm{PM}_{2.5}$ and $\mathrm{PM}_{10}$,

123 densely covering most territories of China, except some regions (e.g., Qinghai). The daily ambient concentrations of $\mathrm{PM}_{2.5}$

124 and $\mathrm{PM}_{10}$ are deemed as the ground truth-values (output), which are acquired by averaging the hourly measurements

125 within a day. It's worth noting only the records with no less than 16 hourly measurements in a single day will be adopted. 


\subsubsection{TROPOMI atmospheric products}

127 The TROPOMI is the single instrument of the Sentinel-5P spacecraft (Veefkind et al., 2012), which covers the wavelength

128 of UltraViolet (UV), Near InfraRed (NIR), and ShortWave InfraRed (SWIR). This hyperspectral spectrometer is devised

129 to provide daily observations of $\mathrm{SO}_{2}, \mathrm{NO}_{2}$, ozone $\left(\mathrm{O}_{3}\right)$, etc., at high spatial resolutions, using passive remote sensing

130 methods. The typical pixel size (near-nadir) is set as $7 \times 3.5 \mathrm{~km}^{2}$ for all spectral bands, except the UV1 band $\left(7 \times 28 \mathrm{~km}^{2}\right)$

131 and SWIR bands $\left(7 \times 7 \mathrm{~km}^{2}\right)$. As for the evaluation, the TROPOMI atmospheric products are routinely compared to ground-

132 based measurements and observations from other instruments carried onboard remote sensing satellites, such as the Ozone

133 Monitoring Instrument (Levelt et al., 2006). The evaluation results show that the qualities of the TROPOMI atmospheric

134 products compile with the mission requirements (Garane et al., 2019; Griffin et al., 2019; Theys et al., 2017). In our study,

135 the records of "sulfurdioxide_total_vertical_column_1 km" and "nitrogendioxide_tropospheric_column" are regarded as

136 the main variates in the proposed approach, which are related to sulfate and nitrate, respectively. In addition, particulate

137 matters $\left(\mathrm{PM}_{2.5}\right.$ and $\left.\mathrm{PM}_{10}\right)$ were discovered to be associated with $\mathrm{O}_{3}$ (Chen et al., 2019, 2020). Therefore, the record of

138 "ozone_total_vertical_column" is also introduced in the proposed approach as one of the auxiliary variates. The

139 information about the TROPOMI atmospheric products used in this study is specifically provided in Table S1 of the

140 supplementary materials.

\section{2.2.3 GEOS-FP assimilated products}

142 The GEOS-FP data assimilation system employs an analysis designed collectively with the National Centers for 143 Environmental Prediction (Lucchesi et al., 2013), which is the current operational met data product from GMAO.

144 Generally, the GEOS-FP can provide the time-averaged (e.g., hourly) assimilated datasets performed at a spatial resolution

145 of $0.25^{\circ} \times 0.3125^{\circ}$, including the atmospheric chemical species and meteorological factors. In our study, the records of the

146 precursor/chemical compositions for $\mathrm{PM}_{2.5}$ and $\mathrm{PM}_{10}$ from GEOS-FP are considered as the main variates of the inputs,

147 including the nitrate-related (i.e., Nitrate Column Mass Concentration), carbon-related (e.g., Organic Carbon Column

148 Mass Concentration), sulfate-related (i.e., SO4 Column Mass Density), etc. Furthermore, a few meteorological factors

149 from GEOS-FP are also adopted as the auxiliary variates in the proposed approach, such as wind speed, specific humidity,

150 and planetary boundary layer height. The relevant information of the GEOS-FP datasets used in our study is presented in

151 the supplementary materials (see Table S1).

\section{2.2.4 Geographical factors}

153 Some geographical factors are usually exploited as the ancillary variates to estimate the ambient concentrations of $\mathrm{PM}_{2.5}$ 154 and $\mathrm{PM}_{10}$ in previous studies, including the land cover classifications (Zhang et al., 2017), population density, NDVI, and 
155 road density (Haklay et al., 2008). Hence, these factors are also introduced in our study, which are associated with $\mathrm{PM}_{2.5}$

156 and $\mathrm{PM}_{10}$. The detailed information about the geographical factors utilized in our study is listed in Table S1 of

157 supplementary materials, which will not be repeatedly described here.

\section{2.2.5 VIIRS DB AOD product}

159 The DB algorithm (Hsu et al., 2019) was first proposed to retrieve aerosol properties of the observations from MODIS

160 over arid/semiarid and urban areas. After a decade, an enhanced DB algorithm was developed and applicable for all areas

161 without snow/ice. In the latest Collection 6.1 (C6.1), the scheme of DB was upgraded once again with several updates,

162 such as the heavy smoke detection. With regard to VIIRS, the procedures are similar to the one for MODIS in C6.1, while

163 a few marked differences still exist. For example, a modified NIR method is employed to acquire the surface reflectance

164 in croplands. The evaluation results showed that the VIIRS DB algorithm performs better than the one for MODIS over

165 Asia (Wang et al., 2020). Due to the similar spatial resolution (6-km) with TROPOMI, the DB AOD from VIIRS is

166 deemed as the main variate in a framework (baseline, AOD-based) for comparison, which is close to the proposed

167 approach (with the same auxiliary variates expect the $\mathrm{O}_{3}$ product from TROPOMI). The specific information about the

168 VIIRS DB AOD product is appended in the supplementary materials (Table S2).

\section{Methodology}

170 The flowchart of the proposed approach is depicted in Figure 2. As can be seen, the datasets (main and auxiliary variates)

171 are initially preprocessed in advance of being adopted as the inputs, e.g., the resampling and missing data recovery.

172 Meanwhile, the ground truth-values (output) are obtained by averaging the hourly ground-based measurements within a

173 day ( $\geq 16$ out of 24$)$. Next, the inputs and ground truth-values ought to be spatially matched considering the differences

174 between them. After the data matching, the data pairs (matched samples) will be fed into the LGBM to train the model.

175 Eventually, a total of three 10-fold Cross-Validation (CV) methods are exploited to validate the performance of the

176 proposed approach. The specific procedures are stated in the following subsections. It's worth noting that the models for

177 the estimation of $\mathrm{PM}_{2.5}$ and $\mathrm{PM}_{10}$ are separately trained. In addition, the methodology of the baseline (AOD-based) is

178 close to the proposed approach, which is appended in Figure S1 of the supplementary materials.

\section{3.1 Data preprocessing}

180 Firstly, the spatial resolutions of the datasets (main and auxiliary variates) should be adjusted to coincident. In our study,

181 the datasets from TROPOMI, GEOS-FP, and geographical factors are resampled to 5-km through the nearest neighbor

182 interpolation (Olivier et al., 2012), bicubic interpolation (Nuno-Maganda et al., 2005), and area-weighted aggregation 
183 (Liu et al., 2019), respectively. In the meantime, the daily datasets of GEOS-FP are acquired by averaging the hourly/3-

184 hour records within a day. Next, the missing values for small regions in the datasets from TROPOMI are filled through 185 the exemplar-based algorithm (Criminisi et al., 2004). Since the missing coverage of the TROPOMI $\mathrm{SO}_{2}$ and $\mathrm{O}_{3}$ products 186 is little, only the examples of the simulated experiments for the TROPOMI $\mathrm{NO}_{2}$ product are demonstrated in the 187 supplementary materials (Figure S2). Besides, the missing values for some pixels in the NDVI product are also filled 188 using the Inverse Distance Weighted interpolation (Wang et al., 2019b).

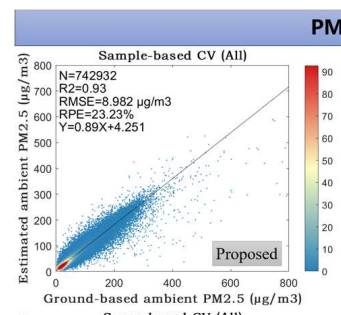

\section{PM10}
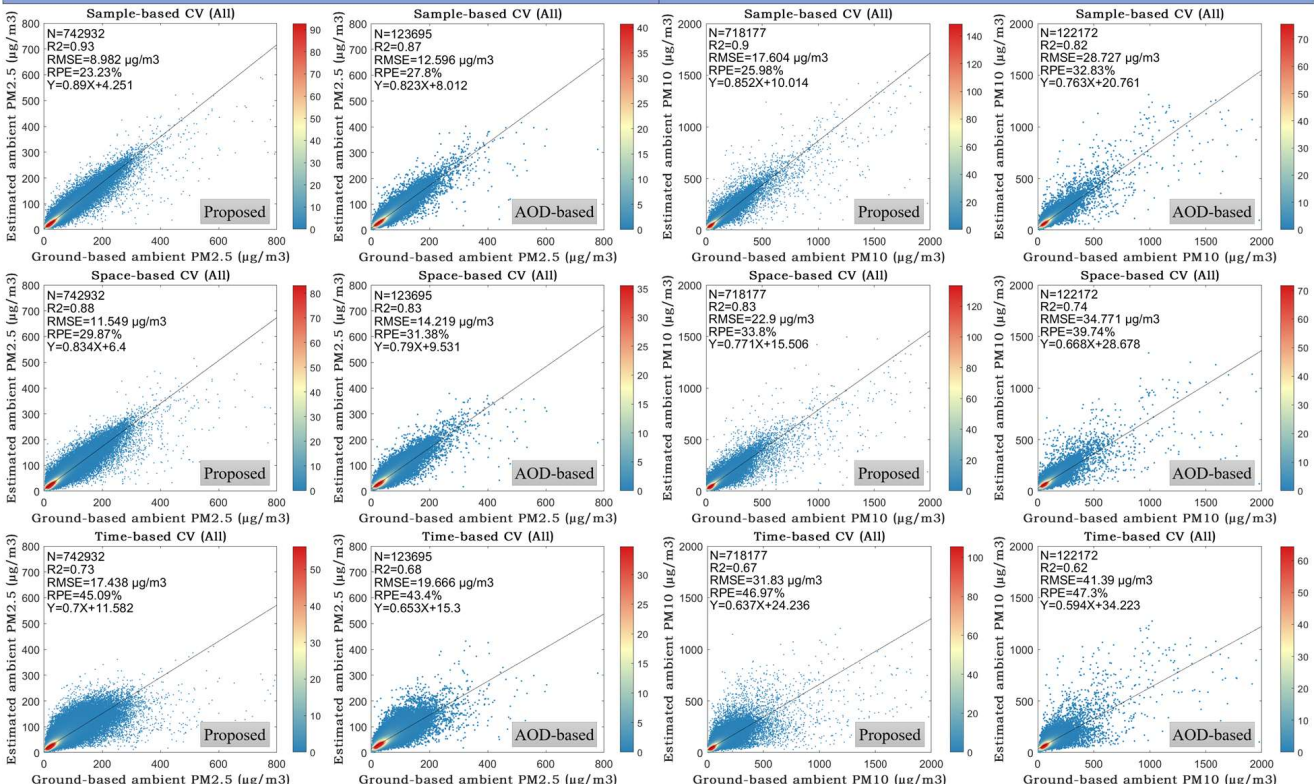

Figure 4. The density scatter plots of the validation results in the study area. The black solid line signifies the fitted line and the color

191 bar denotes the density of samples. Y: estimated ambient concentrations of $\mathrm{PM}_{2.5}$ and $\mathrm{PM}_{10}$; X: ground-based ambient concentrations

192 of $\mathrm{PM}_{2.5}$ and $\mathrm{PM}_{10}$.

193 3.2 Data matching

194 Generally, the datasets (main and auxiliary variates) are grid-based at different spatial resolutions, while ground-based

195 stations only measure the ambient concentrations of $\mathrm{PM}_{2.5}$ and $\mathrm{PM}_{10}$ for small regions. Therefore, the grid-based datasets

196 and ground-based measurements should be spatially matched. In brief, all the ground truth-values falling in one spatial

197 grid (5-km) are averaged to match the datasets from TROPOMI, GEOS-FP, and geographical factors.

\section{3.2 Light Gradient Boosting Machine}

199 LGBM is a newly devised and advanced ensemble learning method based on the Gradient Boosting Decision Tree (Ke et

200 al., 2017). As one of the gradient boosting algorithms, the targets for each training round in LGBM are residual, which 
201 are computed from the truth-value and the estimations after previous training rounds. In other words, the learners in

202 LGBM are mutually associated and consequently the dependencies between learners will be employed. For instance, the 203 overall performance can be significantly improved by assigning higher weights to the samples estimated with larger errors

204 in previous training rounds. Compared to previous gradient boosting algorithms, LGBM is capable of easily achieving

205 higher accuracy with fewer sample features, less memory, and faster speed. In general, the highlights of LGBM mainly

206 consists of two parts: Gradient-based One-Side Sampling and Exclusive Feature Bundling. Both of them are designed to

207 decrease the number of samples in each training round and retained the estimation accuracy. The specific structures of

208 LGBM are complicated and will not be described in our study. For more information, readers could refer to Ke et al.,

2092017.

210 LGBM can process high-dimensional big data of large scale, presenting higher efficiency and better performance by

211 comparison with conventional machine learning methods, e.g., the RF, Generalized Regression Neural Network

212 (Cigizoglu et al., 2005), and Support Vector Regression (Drucker et al., 1997). Hence, it is reasonable to adopt LGBM in

213 our study. The general scheme of the model for estimating the ambient concentrations of $\mathrm{PM}_{2.5}$ and $\mathrm{PM}_{10}$ can be expressed

214 as Eq. (1).

$215 C_{P M}=f\left(V M_{P}, V M_{C C}, V A_{O 3}, V A_{M F}, V A_{G F}\right)$

216 where $C_{P M}$ signifies the estimated ambient concentrations of $\mathrm{PM}_{2.5}$ and $\mathrm{PM}_{10} . f$ denotes the estimation function for the

217 ambient concentrations of $\mathrm{PM}_{2.5}$ and $\mathrm{PM}_{10}$ based on LGBM. $V M_{P}$ and $V M_{C C}$ include the main variates of the precursors

218 and chemical compositions, respectively, for $\mathrm{PM}_{2.5}$ and $\mathrm{PM}_{10} . V A_{O 3}, V A_{M F}$, and $V A_{G F}$ represent the auxiliary variates of

219 the $\mathrm{O}_{3}$ from TROPOMI, meteorological factors, and geographical factors, respectively. The detailed information about

220 each variate can be found in Table S1 and S3 of the supplementary materials. The setting of the LGBM parameters is

221 listed in Table S4.

2223.3 Validation methods

223 To sufficiently validate the performance of the proposed approach, a total of three 10 -fold CV methods, i.e., the sample-

224 based CV, space-based CV, and time-based CV, are exploited in our study. With regard to the sample-based CV, all the

225 matched samples are divided into 10 folds at random (the number is approximately identical). Next, nine folds are

226 employed to train the model and the remaining one is considered for the validation. At last, the previous step is repeatedly

227 performed 10 times and consequently each fold can be validated. As for the space-based CV and time-based CV, the steps

228 are close to those for the sample-based CV. The only distinction is that the 5-km spatial grids (space-based CV) or temporal

229 sequences (time-based CV) are randomly separated into 10 folds, rather than the matched samples. The schematic diagram 
230 of the three 10-fold CV methods is illustrated in Figure 3. In this study, the estimated results are validated through three

231 metrics: the coefficient of determination $\left(\mathrm{R}^{2}\right)$, the Root Mean Square Error (RMSE), and the Relative Percentage Error

232 (RPE). It is worth noting that all the metrics are computed at the significance levels of $\mathrm{p}<0.01$ in our study.

233 Table 1. The validation results for the proposed and AOD-based considering whether the values of VIIRS DB AOD are missing. VR: 234 valid regions (the values of VIIRS DB AOD are available); MR: missing regions (the values of VIIRS DB AOD are unavailable); T: 235 true; F: false.

\begin{tabular}{|c|c|c|c|c|c|c|c|c|c|c|}
\hline \multirow{2}{*}{$\mathrm{CV}$ method } & \multirow{2}{*}{ Region } & \multirow{2}{*}{ Approach } & \multicolumn{4}{|c|}{$\mathrm{PM}_{2.5}$} & \multicolumn{4}{|c|}{$\mathrm{PM}_{10}$} \\
\hline & & & $\mathrm{N}$ & $\mathrm{R}^{2}$ & RMSE & RPE & $\mathrm{N}$ & $\mathrm{R}^{2}$ & RMSE & RPE \\
\hline \multirow{3}{*}{ Sample-based } & \multirow[b]{2}{*}{ VR } & Proposed & \multirow[b]{2}{*}{122614} & 0.92 & $9.753 \mu \mathrm{g} / \mathrm{m}^{3}$ & $21.61 \%$ & \multirow[b]{2}{*}{121098} & 0.89 & $22.295 \mu \mathrm{g} / \mathrm{m}^{3}$ & $25.53 \%$ \\
\hline & & AOD-based & & 0.87 & $12.535 \mu \mathrm{g} / \mathrm{m}^{3}$ & $27.77 \%$ & & 0.82 & $28.436 \mu \mathrm{g} / \mathrm{m}^{3}$ & $32.57 \%$ \\
\hline & MR & Proposed & 620742 & 0.93 & $8.826 \mu \mathrm{g} / \mathrm{m}^{3}$ & $23.61 \%$ & 597471 & 0.9 & $16.517 \mu \mathrm{g} / \mathrm{m}^{3}$ & $25.9 \%$ \\
\hline \multirow{3}{*}{ Space-based } & \multirow{2}{*}{ VR } & Proposed & \multirow{2}{*}{122614} & 0.87 & $12.43 \mu \mathrm{g} / \mathrm{m}^{3}$ & $27.54 \%$ & \multirow{2}{*}{121098} & 0.82 & $28.878 \mu \mathrm{g} / \mathrm{m}^{3}$ & $33.07 \%$ \\
\hline & & AOD-based & & 0.83 & $14.311 \mu \mathrm{g} / \mathrm{m}^{3}$ & $31.7 \%$ & & 0.74 & $34.803 \mu \mathrm{g} / \mathrm{m}^{3}$ & $39.86 \%$ \\
\hline & MR & Proposed & 620742 & 0.88 & $11.691 \mu \mathrm{g} / \mathrm{m}^{3}$ & $31.28 \%$ & 597471 & 0.83 & $21.629 \mu \mathrm{g} / \mathrm{m}^{3}$ & $33.92 \%$ \\
\hline \multirow{3}{*}{ Time-based } & \multirow{2}{*}{ VR } & Proposed & & 0.71 & $18.795 \mu \mathrm{g} / \mathrm{m}^{3}$ & $41.64 \%$ & \multirow{2}{*}{121098} & 0.65 & $39.906 \mu \mathrm{g} / \mathrm{m}^{3}$ & $45.7 \%$ \\
\hline & & AOD-based & 122614 & 0.68 & $19.58 \mu \mathrm{g} / \mathrm{m}^{3}$ & $43.38 \%$ & & 0.62 & $41.181 \mu \mathrm{g} / \mathrm{m}^{3}$ & $47.16 \%$ \\
\hline & MR & Proposed & 620742 & 0.73 & $17.153 \mu \mathrm{g} / \mathrm{m}^{3}$ & $45.89 \%$ & 597471 & 0.67 & $29.91 \mu \mathrm{g} / \mathrm{m}^{3}$ & $46.91 \%$ \\
\hline
\end{tabular}

236 Note: The numbers of the matched samples in VR are less than those for the AOD-based (see Figure 4) since the original swath files

237 of TROPOMI are not available on several days.

\section{Experiment results and discussions}

\subsection{Overall validation results}

240 The density scatter plots of the sample-based CV, space-based CV, and time-based CV for the estimated ambient

241 concentrations of $\mathrm{PM}_{2.5}$ and $\mathrm{PM}_{10}$ are depicted in Figure 4. As can be seen, the estimated concentrations through the

242 proposed approach are validated with sufficient matched samples (742932 and 718177) in the study area, indicating the

243 reliability of the validation results. By contrast, the number of matched samples for the AOD-based (123695 and 122172)

244 is much less due to the missing values in the VIIRS DB AOD product. As for all matched samples, the estimated ambient

245 concentrations of $\mathrm{PM}_{2.5}$ and $\mathrm{PM}_{10}$ through the proposed approach achieve a better performance compared to those through

246 the AOD-based, with higher $\mathrm{R}^{2} \mathrm{~s}$ for three $\mathrm{CV}$ methods (e.g., $\mathrm{PM}_{2.5}$ : 0.93, 0.88, and 0.73). In the meantime, the

247 performance difference of the estimation between $\mathrm{PM}_{2.5}$ and $\mathrm{PM}_{10}$ for the proposed approach is smaller than that for the

248 AOD-based, suggesting the robustness and applicability of our approach. To further validate the proposed approach, the 
249 experiment results of some related previous works over China are provided in the supplementary materials. It is worth 250 noting that only the metrics computed from the estimated results of 2019 (a whole year) in our study are presented for 251 fairness. As listed in Table S5, the proposed approach shows a satisfactory performance by comparison with these works, 252 which is reflected in the estimation accuracy or completeness of valid values.
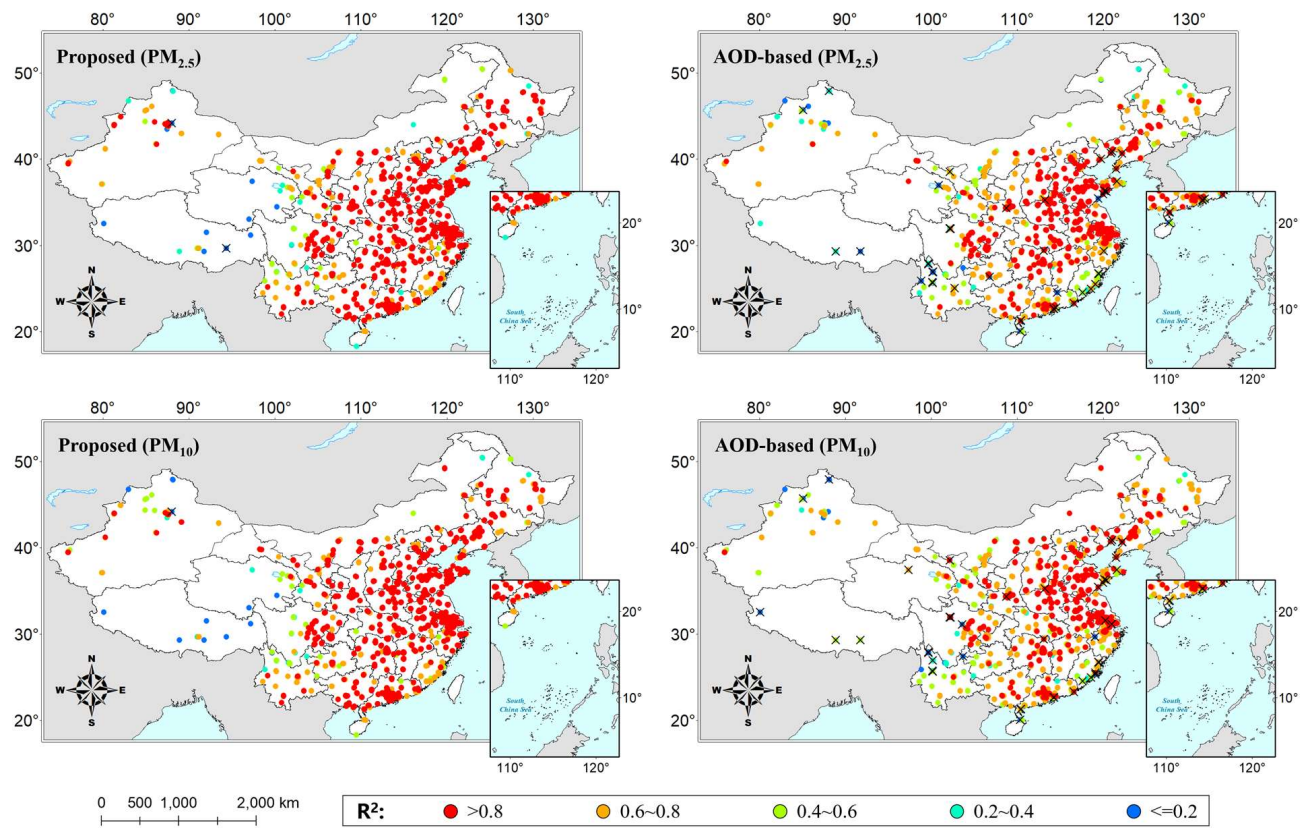

$0.6 \sim 0.8$

$0.4 \sim 0.6$

$0.2 \sim 0.4$

$0<0.2$

254 Figure 5. The spatial distribution of $\mathrm{R}^{2} \mathrm{~s}$ for the space-based $\mathrm{CV}$ at each matched grid over China. The black crosses denote that the 255 significance levels (p) of the metrics are not less than 0.01 at these matched grids.

\section{$256 \quad 4.2$ Seasonal and regional validation results}

257 The density scatter plots of three CV methods for four seasons (2019), i.e., DJF (Dec., Jan., and Feb.), MAM (Mar., Apr.,

258 and May.), JJA (Jun., Jul., and Aug.), and SON (Sep., Oct., and Nov.), are appended in the supplementary materials. As

259 demonstrated in Figure S3-S6, the performance of the proposed approach is also as expected in different seasons, of which

260 the metrics generally overmatch those of the AOD-based, especially for JJA. Next, the matched samples are divided into

261 two parts according to whether the values of VIIRS DB AOD are missing to compare the proposed approach and the

262 AOD-based under the equal condition. As listed in Table 1, the proposed approach presents a superior estimation accuracy

263 of $\mathrm{PM}_{2.5}$ and $\mathrm{PM}_{10}$ for three $\mathrm{CV}$ methods in the valid regions, with differences of $0.03-0.08$ in $\mathrm{R}^{2} \mathrm{~s}$ and $1.46-7.04 \%$ in

264 RPEs. Besides, it's observed that the proposed approach performs well in the missing regions, showing similar metrics

265 to those in the valid regions. 

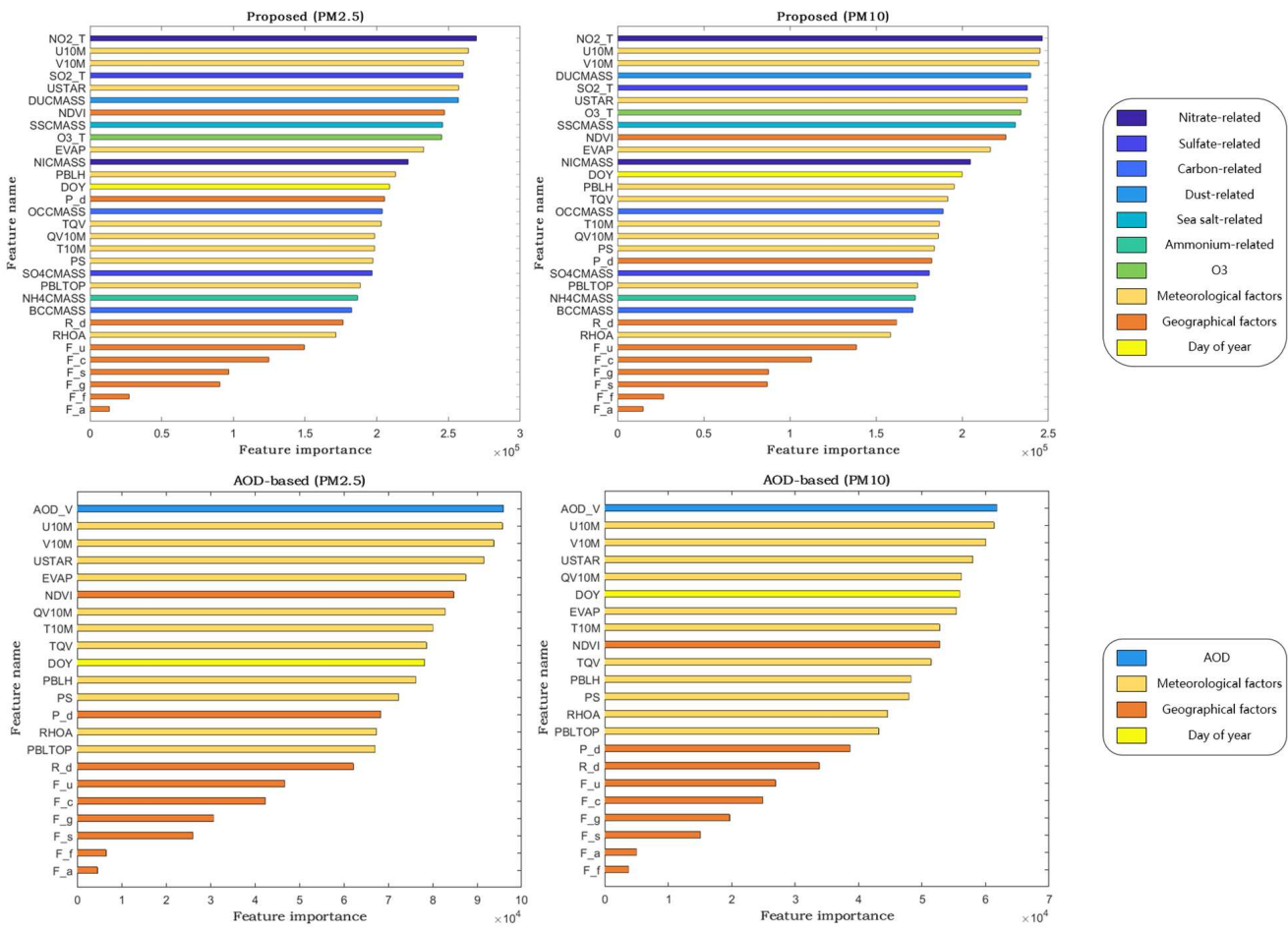

267 Figure 6. The bar graphs of the feature importance for the proposed and AOD-based. The full names of the features can be found in 268 Table S3.

\section{4.3 Grid-based validation results}

270 The performance at each matched grid is important, which is able to reveal the influence from the spatial heterogeneity

271 of $\mathrm{PM}_{2.5}$ and $\mathrm{PM}_{10}$. Since the division of matched samples as per spatial grids could represent the spatial patterns, the

272 space-based CV results are adopted to map the spatial distributions of the metrics at each matched grid in our study. As

273 shown in Figure 5, a total of 974/79.6\% and 945/77.27\% matched grids present the $\mathrm{R}^{2} \mathrm{~s}>0.8(\mathrm{p}<0.01)$ of $\mathrm{PM}_{2.5}$ and $\mathrm{PM}_{10}$

274 for the proposed approach, respectively. In contrast, the numbers of the matched grids showing the $\mathrm{R}^{2} \mathrm{~s}>0.8(\mathrm{p}<0.01)$

275 visibly reduce (by $352 / 28.78 \%$ of $\mathrm{PM}_{2.5}$ and $420 / 34.34 \%$ of $\mathrm{PM}_{10}$ ) for the AOD-based. Meanwhile, the proposed approach

276 also displays higher $\mathrm{R}^{2} \mathrm{~s}$ compared to the AOD-based in some regions, where the ground-based stations are sparse, such

277 as Xinjiang. In addition, the spatial distributions of RMSEs, RPEs, and sample numbers for the space-based CV at each

278 matched grid are appended in Figure S7-S9 of the supplementary materials. Since RMSE is one of the absolute metrics,

279 which are relevant to the magnitudes, the spatial distribution distinctions of RMSEs at matched grids for the proposed

280 and AOD-based will be not discussed. By comparison with $\mathrm{R}^{2} \mathrm{~s}$, the differences of the matched grids between the proposed

281 and AOD-based are smaller for RPEs ( $<=30 \%$, $<<0.01$ ), with the numbers of $126 / 10.3 \%$ and $150 / 12.26 \%$ of $\mathrm{PM}_{2.5}$ and 
$282 \mathrm{PM}_{10}$, respectively. From Figure S9, most of the matched grids exceed 600 samples for the proposed approach, while

283 almost all the sample numbers of the AOD-based are less than 300. As a consequence, the non-significant metrics

$284(\mathrm{p}>=0.01)$ are numerous in the space-based CV results through the AOD-based due to the missing coverage.

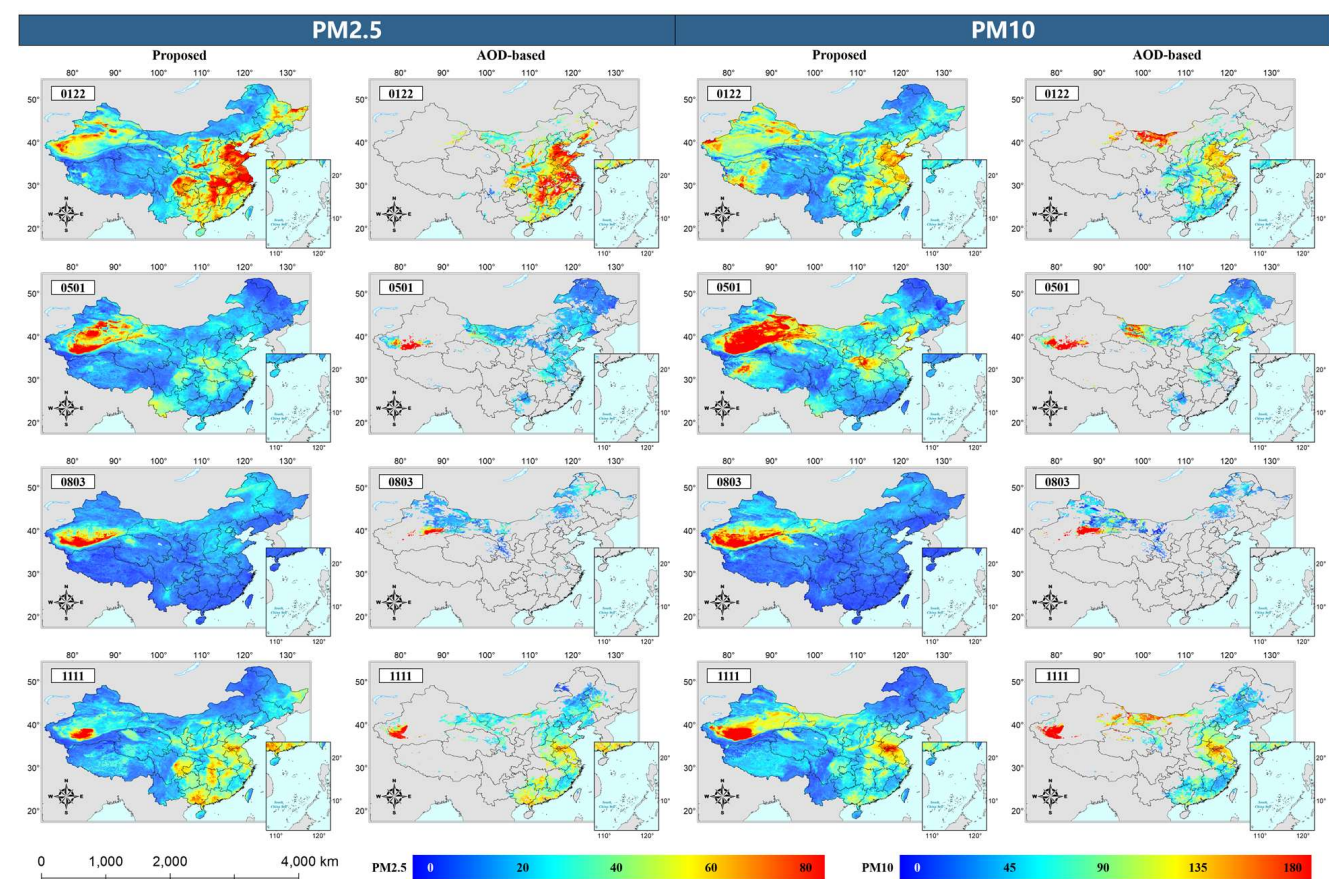

Figure 7. The daily estimated ambient concentrations of $\mathrm{PM}_{2.5}$ and $\mathrm{PM}_{10}$ for the proposed and AOD-based across China in 2019. The color bars represent the values of the estimated results. Units: $\mu \mathrm{g} / \mathrm{m}^{3}$.

\section{$288 \quad 4.4$ Feature importance of variates}

289 The bar (pie) graphs that provide the feature importance (percentages) of the inputs in the proposed and AOD-based are

290 illustrated in Figure 6. With regard to the proposed approach, the variates from TROPOMI, i.e., NO2_T and SO2_T, play

291 an important part in estimating the results, which are the precursors for $\mathrm{PM}_{2.5}$ and $\mathrm{PM}_{10}$. In the meantime, the rank of

292 DUCMASS rises for the estimation of $\mathrm{PM}_{10}$ compared to that of $\mathrm{PM}_{2.5}$, indicating the flexibility of our approach.

293 Furthermore, all the variates of the precursors \& chemical compositions for $\mathrm{PM}_{2.5}$ and $\mathrm{PM}_{10}$ (e.g., carbon-related)

294 positively contribute to the estimation through the proposed approach, which is as expected. By contrast, most of the 295 contributions in the results estimated by the AOD-based mainly stem from the meteorological factors. 


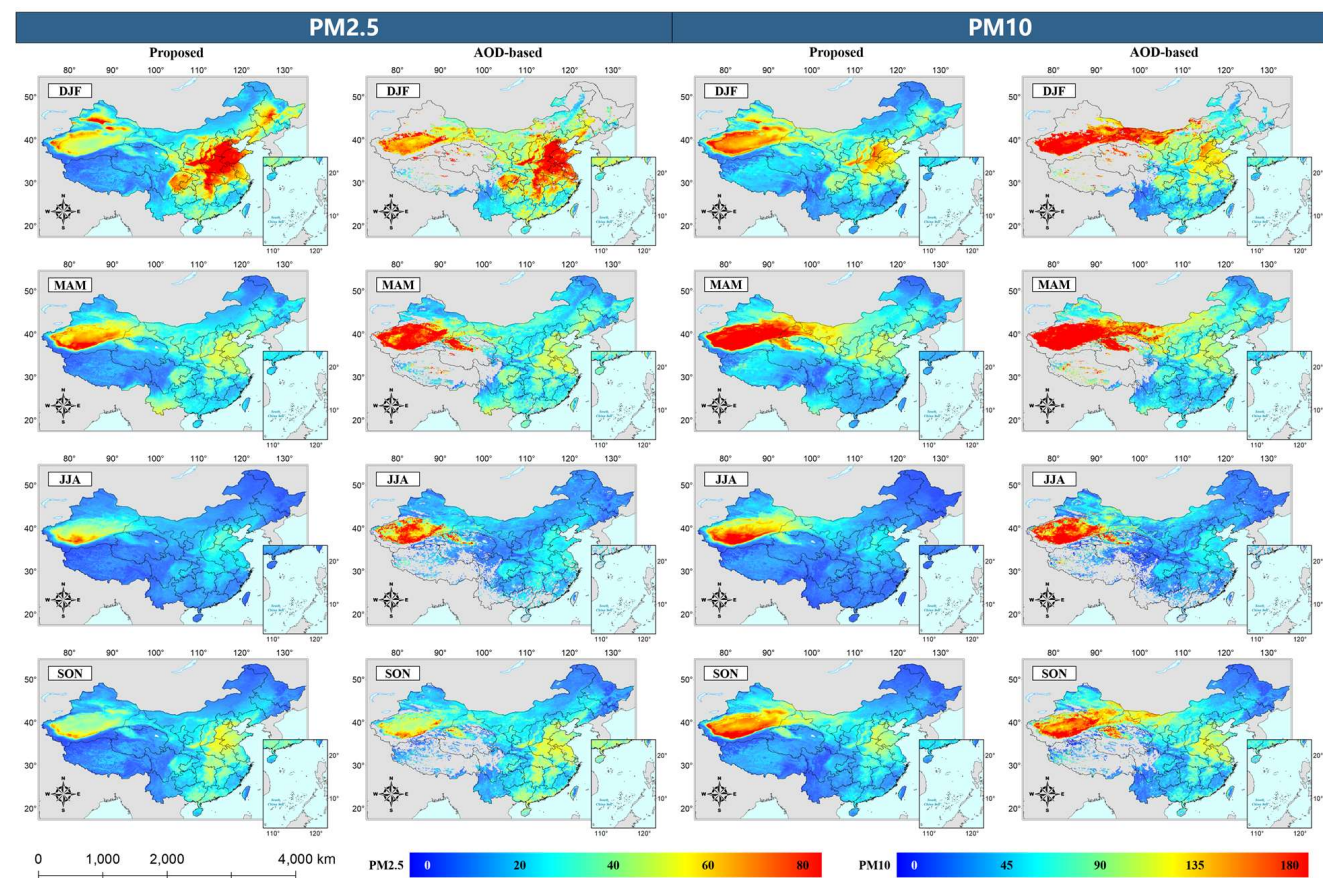

Figure 8. The seasonal estimated ambient concentrations of $\mathrm{PM}_{2.5}$ and $\mathrm{PM}_{10}$ for the proposed and AOD-based across China in 2019.

The color bars represent the values of the estimated results. Units: $\mu \mathrm{g} / \mathrm{m}^{3}$.

\subsection{Evaluation of the spatial distribution}

300 At first, the estimated ambient concentrations of $\mathrm{PM}_{2.5}$ and $\mathrm{PM}_{10}$ for a total of four days, i.e., 20190122, 20190501,

30120190803 , and 20191111, are utilized to evaluate the spatial distribution of the daily estimated results. As demonstrated

302 in Figure 7, the daily estimated results through the proposed approach present consecutive spatial distribution without

303 distinctly incorrect structures, suggesting that our approach is reliable. On the contrary, the absence of a large scale can

304 be discovered in the daily ambient concentrations of $\mathrm{PM}_{2.5}$ and $\mathrm{PM}_{10}$ estimated by the AOD-based. Next, the estimated

305 results for four seasons in 2019 are also mapped to evaluate the seasonal spatial distribution. As illustrated in Figure 8,

306 the proposed approach is capable of exactly expressing the seasonal variations of $\mathrm{PM}_{2.5}$ and $\mathrm{PM}_{10}$. For instance, the high

307 values of the seasonal estimated $\mathrm{PM}_{2.5}$ principally emerge in DJF, which is caused by the heating emissions (e.g., fossil

308 fuels combustion) and adverse meteorological conditions (Cao et al., 2012); The seasonal estimated ambient

309 concentrations of $\mathrm{PM}_{10}$ mainly appear large in MAM due to the sand storms and dry weathers (Li et al., 2017c). With

310 regard to most areas of China (except the Northwest), the seasonal estimated results through the proposed and AOD-based

311 display similar spatial patterns, with the distinctions of the values. In DJF, the differences between the proposed and AOD-

312 based are the greatest for four seasons, which likely results from the influence of the missing values (AOD) on time-

313 averaged results. Meanwhile, it is observed that the seasonal estimated ambient concentrations of $\mathrm{PM}_{2.5}$ and $\mathrm{PM}_{10}$ through 
314 the proposed are generally larger than those through the AOD-based in arid/semiarid regions, such as Xinjiang. As stated 315 in Section 4.3, the proposed approach shows higher $\mathrm{R}^{2} \mathrm{~s}$ at matched grids compared to the AOD-based in Xinjiang.

316 Therefore, the discrepancy possibly derives from the overestimation of VIIRS DB AOD in arid/semiarid regions (Sayer 317 et al., 2019; Wang et al., 2020).
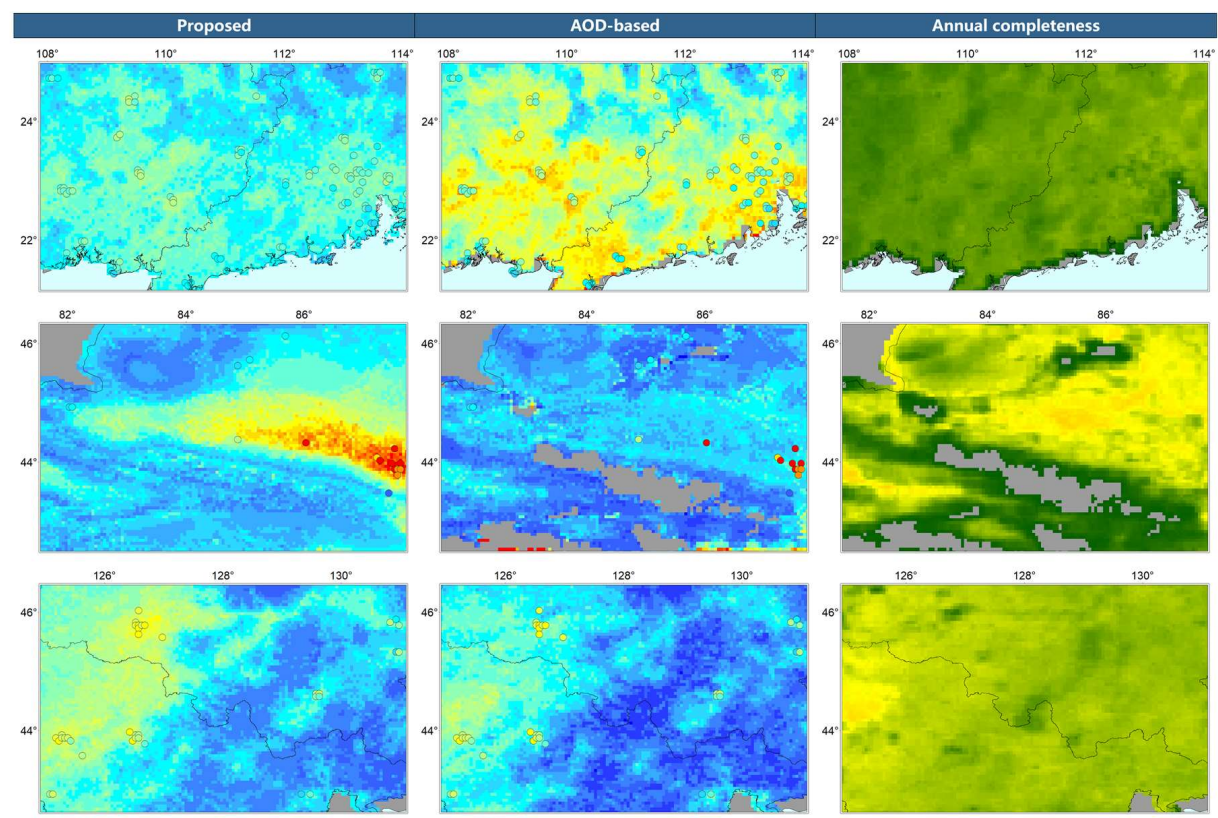<smiles>CC12C[C]3C1C32</smiles>

$0,75 \quad 150$

Figure 9. The annual estimated ambient concentrations of $\mathrm{PM}_{2.5}$ for the proposed and AOD-based over local regions in 2019. The left color bar represents the values of the estimated results and ground truth-values. The right color bar denotes the completeness of VIIRS DB AOD. Units: $\mu \mathrm{g} / \mathrm{m}^{3}$ for $\mathrm{PM}_{2.5}$ and \% for completeness.

\section{4.6 Discussions of the time-averaged results}

323 To further explore the influence of the missing values (AOD) on time-averaged results, the annual estimated ambient

324 concentrations of $\mathrm{PM}_{2.5}$ and $\mathrm{PM}_{10}$ are mapped over local regions in Figure 9 and S10. In the meantime, the annual ground

325 truth-values are also provided in the figures, which is conducive to indicating the real spatial distribution of $\mathrm{PM}_{2.5}$ and

$326 \mathrm{PM}_{10}$. As depicted in Figure 9, the annual estimated ambient concentrations of $\mathrm{PM}_{2.5}$ through the AOD-based present

327 great distinctions by comparison with the ground truth-values in the selected regions. This suggests that the influence of

328 the missing values in the AOD product on time-averaged results is nonnegligible. Namely, the AOD-based likely

329 incorrectly estimates the time-averaged (e.g., annual) ambient concentrations of $\mathrm{PM}_{2.5}$ in some regions. By contrast, the

330 proposed approach achieves a satisfactory performance compared to the ground truth-values. As for $\mathrm{PM}_{10}$, the discovery 
331 is similar (see Figure S10) and will not be repeatedly stated. The full-coverage results estimated by the proposed approach

332 are conducive to the researches on $\mathrm{PM}_{2.5}$ and $\mathrm{PM}_{10}$ over the regions where the $\mathrm{AOD}$ values are missing. In addition, the 333 box plots displaying the variations of the absolute relative difference between annual estimated results (over China) 334 through the proposed and AOD-based (see Eq. s1) with the increment of annual AOD completeness are shown in Figure 335 10. It can be observed that the overall means of the absolute relative difference are $26.54 \%$ and $29.78 \%$ for $\mathrm{PM}_{2.5}$ and $336 \mathrm{PM}_{10}$, respectively. Meanwhile, the absolute relative difference (mean) and annual AOD completeness appear negative 337 correlations, especially for the regions where the AOD values are largely missing $(<20 \%)$.
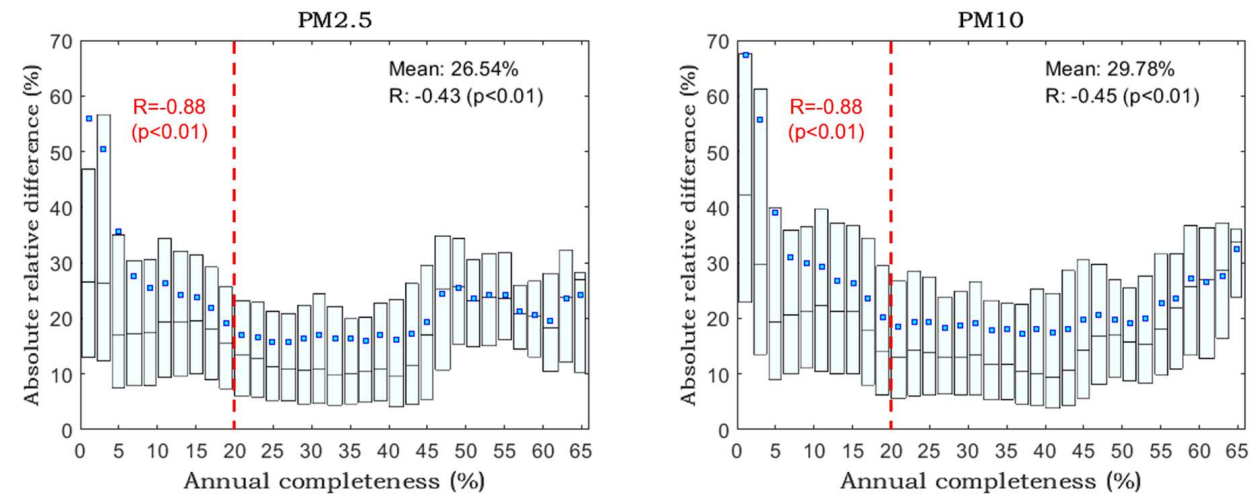

339 Figure 10. The variations (box plots) of the absolute relative difference between annual estimated results (over China) through the proposed and AOD-based with the increment of annual AOD completeness. For each box, the middle line, rectangle dot, top, and

341 bottom hinges are the median, mean, $25^{\text {th }}$, and $75^{\text {th }}$ percentiles, respectively.

\section{Conclusions}

343 In this study, a novel approach is developed, which can estimate the daily full-coverage ambient concentrations of $\mathrm{PM}_{2.5}$ 344 and $\mathrm{PM}_{10}$ considering their precursors \& chemical compositions at a 5-km $\left(0.05^{\circ}\right)$ spatial resolution over China from 345 TROPOMI and GEOS-FP. To sufficiently fuse the multi-source data, one of the ensemble learning methods, i.e., LGBM,

346 is employed to train the estimation models. In the meantime, the DB AOD product from VIIRS is applied in a similar

347 framework (AOD-based) for comparison. The validation results show that the ambient concentrations are well estimated

348 through the proposed approach in the study area, with the sample-based CV R ${ }^{2}$ s and RMSEs of $0.93(0.9)$ and 8.982

349 (17.604) $\mu \mathrm{g} / \mathrm{m}^{3}$ for $\mathrm{PM}_{2.5}\left(\mathrm{PM}_{10}\right)$, respectively. Meanwhile, the proposed approach achieves better performance than the

350 AOD-based in different situations (e.g., overall and seasonal), suggesting that our approach is reliable. Compared to the

351 related previous works, the estimation accuracy of the proposed approach is also satisfactory. For the feature importance,

352 all the variates of the precursors \& chemical compositions for $\mathrm{PM}_{2.5}$ and $\mathrm{PM}_{10}$ (e.g., carbon-related) positively contribute 353 to the estimation in our approach, which is as expected. As for the mapping, the estimated results through the proposed 
354 approach appear consecutive spatial distribution without visibly incorrect structures and can exactly express the seasonal 355 variations of $\mathrm{PM}_{2.5}$ and $\mathrm{PM}_{10}$. In addition, it is discovered that the AOD-based likely incorrectly estimates the time356 averaged ambient concentrations of $\mathrm{PM}_{2.5}$ and $\mathrm{PM}_{10}$. The full-coverage estimated results through the proposed approach 357 are conducive to the studies on $\mathrm{PM}_{2.5}$ and $\mathrm{PM}_{10}$ in the regions where the AOD values are missing.

\section{Author contributions}

359 YW designed the study, collected and processed the data, analyzed the results, and wrote the paper. QQY provided 360 constructive comments on the paper. TWL, SYT, and LPZ revised the paper. All authors contributed to the study.

\section{Acknowledgments}

362 This work was supported by the National Natural Science Foundation of China (No. 41922008). The authors would like 363 to be greatly grateful to the institutions for providing the datasets used in this paper.

\section{References}

365 Bai, Z., Wang, J., Wang, M., Gao, M., and Sun, J.: Accuracy assessment of multi-source gridded population distribution 366 datasets in China, Sustainability., 10(5), 1363, doi: 10.3390/su10051363, 2018.

367 Baker, K. and Scheff, P.: Photochemical model performance for PM2.5 sulfate, nitrate, ammonium, and precursor species $368 \mathrm{SO} 2, \mathrm{HNO} 3$, and NH3 at background monitor locations in the central and eastern United States, Atmos. Environ., 41(29), 369 6185-6195, doi: 10.1016/j.atmosenv.2007.04.006, 2007.

370 Beck, P. S., Atzberger, C., Høgda, K. A., Johansen, B., and Skidmore, A. K.: Improved monitoring of vegetation dynamics 371 at very high latitudes: A new method using MODIS NDVI, Remote Sens. Environ., 100(3), 321-334, doi: 372 10.1016/j.rse.2005.10.021, 2006.

373 Cao, J. J., Shen, Z. X., Chow, J. C., Watson, J. G., Lee, S. C., Tie, X. X., and Han, Y. M.: Winter and summer PM2.5 374 chemical compositions in fourteen Chinese cities, J. Air Waste Manage., 62(10), 1214-1226, doi: 375 10.1080/10962247.2012.701193, 2012.

376 Chen, G., Wang, Y., Li, S., Cao, W., Ren, H., Knibbs, L. D., and Guo, Y.: Spatiotemporal patterns of PM10 concentrations 377 over China during 2005-2016: A satellite-based estimation using the random forests approach, Environ. Pollut., 242, 605378 613, doi: 10.1016/j.envpol.2018.07.012, 2018.

379 Chen, J., Shen, H., Li, T., Peng, X., Cheng, H., and Ma, C.: Temporal and Spatial Features of the Correlation between 380 PM2.5 and O3 Concentrations in China, Int. J. Environ. Res. Public Health., 16(23), 4824, doi: 10.3390/ijerph16234824, 
382 Chen, L., Xing, J., Mathur, R., Liu, S., Wang, S., and Hao, J.: Quantification of the enhancement of PM2.5 concentration 383 by the downward transport of ozone from the stratosphere, Chemosphere., 126907, doi: 384 10.1016/j.chemosphere.2020.126907, 2020.

385 Cigizoglu, H. K.: Application of generalized regression neural networks to intermittent flow forecasting and estimation, 386 J. Hydrol. Eng., 10(4), 336-341, doi: 10.1061/(ASCE)1084-0699(2005)10:4(336), 2005.

387 Criminisi, A., Pérez, P., and Toyama, K.: Region filling and object removal by exemplar-based image inpainting, IEEE T. 388 Image. Process., 13(9), 1200-1212, doi: 10.1109/TIP.2004.833105, 2004.

389 Crippa, M., Janssens-Maenhout, G., Guizzardi, D., Van Dingenen, R., and Dentener, F.: Contribution and uncertainty of 390 sectorial and regional emissions to regional and global PM2.5 health impacts, Atmos. Chem. Phys., 19(7), 5165-5186, 391 doi: 10.5194/acp-19-5165-2019, 2019.

392 Dabek-Zlotorzynska, E., Dann, T. F., Martinelango, P. K., Celo, V., Brook, J. R., Mathieu, D., and Austin, C. C.: Canadian 393 National Air Pollution Surveillance (NAPS) PM2.5 speciation program: Methodology and PM2.5 chemical composition 394 for the years 2003-2008, Atmos. Environ., 45(3), 673-686, doi: 10.1016/j.atmosenv.2010.10.024, 2011.

395 Drucker, H., Burges, C. J., Kaufman, L., Smola, A. J., and Vapnik, V.: Support vector regression machines, In Advances 396 in neural information processing systems., 155-161, 1997.

397 Engel-Cox, J., Oanh, N. T. K., van Donkelaar, A., Martin, R. V., and Zell, E.: Toward the next generation of air quality 398 monitoring: particulate matter, Atmos. Environ., 80, 584-590, doi: 10.1016/j.atmosenv.2013.08.016, 2013.

399 Finlayson-Pitts, B. J. and Pitts, J. N.: Tropospheric air pollution: ozone, airborne toxics, polycyclic aromatic hydrocarbons, 400 and particles, Science., 276(5315), 1045-1051, doi: 10.1126/science.276.5315.1045, 1997.

401 Garane, K., Koukouli, M. E., Verhoelst, T., Lerot, C., Heue, K. P., Fioletov, V., and Goutail, F.: TROPOMI/S5P total ozone 402 column data: global ground-based validation and consistency with other satellite missions, Atmos. Meas. Tech., 12(10), 403 5263-5287, doi: 10.5194/amt-12-5263-2019, 2019.

404 Griffin, D., Zhao, X., McLinden, C. A., Boersma, F., Bourassa, A., Dammers, E., and Hayden, K.: High-resolution 405 mapping of nitrogen dioxide with TROPOMI: First results and validation over the Canadian oil sands, Geophys. Res. 406 Lett., 46(2), 1049-1060, doi: 10.1029/2018GL081095, 2019.

407 Guo, J., Xia, F., Zhang, Y., Liu, H., Li, J., Lou, M., and Zhai, P.: Impact of diurnal variability and meteorological factors 408 on the PM2.5-AOD relationship: Implications for PM2.5 remote sensing, Environ. Pollut., 221, 94-104, doi: 409 10.1016/j.envpol.2016.11.043, 2017.

410 Haklay, M. and Weber, P.: Openstreetmap: User-generated street maps, IEEE Pervas. Comput., 7(4), 12-18, doi: 
411 10.1109/MPRV.2008.80, 2008.

412 Hall, J. V., Winer, A. M., Kleinman, M. T., Lurmann, F. W., Brajer, V., and Colome, S. D.: Valuing the health benefits of 413 clean air, Science., 255(5046), 812-817, doi: 10.1126/science.1536006, 1992.

414 Hsu, N. C., Lee, J., Sayer, A. M., Kim, W., Bettenhausen, C., and Tsay, S. C.: VIIRS Deep blue aerosol products over 415 land: Extending the EOS long-term aerosol data records, J. Geophys. Res. Atmos., 124(7), 4026-4053, doi: 416 10.1029/2018JD029688, 2019.

417 Hua, Z., Sun, W., Yang, G., and Du, Q.: A full-coverage daily average PM2.5 retrieval method with two-stage IVW fused 418 MODIS C6 AOD and two-stage GAM model, Remote Sens., 11(13), 1558, doi: 10.3390/rs11131558, 2019.

419 Ke, G., Meng, Q., Finley, T., Wang, T., Chen, W., Ma, W., and Liu, T. Y.: Lightgbm: A highly efficient gradient boosting 420 decision tree, In Advances in neural information processing systems., 3146-3154, 2017.

421 Lee, R. E.: The size of suspended particulate matter in air: size distributions of ambient aerosols must be studied in order 422 to determine their effects on the environment, Science., 178(4061), 567-575, doi: 10.1126/science.178.4061.567, 1972.

423 Levelt, P. F., van den Oord, G. H., Dobber, M. R., Malkki, A., Visser, H., de Vries, J., and Saari, H.: The ozone monitoring 424 instrument, IEEE T. Geosci. Remote Sen., 44(5), 1093-1101, doi: 10.1109/TGRS.2006.872333, 2006

425 Levy, R. C., Mattoo, S., Munchak, L. A., Remer, L. A., Sayer, A. M., Patadia, F., and Hsu, N. C.: The Collection 6 MODIS 426 aerosol products over land and ocean, Atmos. Meas. Tech., 6(11), 2989, doi: 10.5194/amt-6-2989-2013, 2013.

427 Li, T., Shen, H., Yuan, Q., Zhang, X., and Zhang, L.: Estimating ground-level PM2.5 by fusing satellite and station 428 observations: a geo-intelligent deep learning approach, Geophys. Res. Lett., 44(23), 11-985, doi: 10.1002/2017GL075710, $4292017 \mathrm{a}$

430 Li, T., Shen, H., Yuan, Q., and Zhang, L.: Geographically and temporally weighted neural networks for satellite-based 431 mapping of ground-level PM2.5, ISPRS J. Photogramm. Remote Sens., 167, 178-188, doi: $43210.1016 /$ j.isprsjprs.2020.06.019, 2020.

433 Li, M., Liu, H., Geng, G., Hong, C., Liu, F., Song, Y., and Zhang, Q.: Anthropogenic emission inventories in China: a 434 review, Natl. Sci. Rev., 4(6), 834-866, doi: 10.1093/nsr/nwx150, 2017 b.

435 Li, X., Ma, Y., Wang, Y., Liu, N., and Hong, Y.: Temporal and spatial analyses of particulate matter (PM10 and PM2.5) 436 and its relationship with meteorological parameters over an urban city in northeast China, Atmos. Res., 198, 185-193, doi: 437 10.1016/j.atmosres.2017.08.023, 2017c.

438 Lin, C., Lau, A. K., Fung, J. C., Lao, X. Q., Li, Y., and Li, C.: Assessing the effect of the long-term variations in aerosol 439 characteristics on satellite remote sensing of PM2.5 using an observation-based model, Environ. Sci. Technol., 53(6), 440 2990-3000, doi: 10.1021/acs.est.8b06358, 2019. 
441 Lin, C. Q., Liu, G., Lau, A. K. H., Li, Y., Li, C. C., Fung, J. C. H., and Lao, X. Q.: High-resolution satellite remote sensing 442 of provincial PM2.5 trends in China from 2001 to 2015, Atmos. Environ., 180, 110-116, doi: 443 10.1016/j.atmosenv.2018.02.045, 2018.

444 Liu, J., Zheng, Y., Geng, G., Hong, C., Li, M., Li, X., and He, K.: Decadal changes in anthropogenic source contribution 445 of PM2.5 pollution and related health impacts in China, 1990-2015, Atmos. Chem. Phys., 20(13), 7783-7799, doi: 446 10.5194/acp-20-7783-2020, 2020.

447 Liu, D., Di, B., Luo, Y., Deng, X., Zhang, H., Yang, F., and Yu, Z.: Estimating ground-level CO concentrations across 448 China based on the national monitoring network and MOPITT: potentially overlooked CO hotspots in the Tibetan Plateau, 449 Atmos. Chem. Phys., 19(19), 12413-12430, doi: 10.5194/acp-19-12413-2019, 2019.

450 Lucchesi, R.: File Specification for GEOS-5 FP (Forward Processing), 2013. 451 http://acmg.seas.harvard.edu/geos/wiki_docs/geos5/GEOS_5_FP_File_Specification_ON4v1_0.pdf.

452 Ma, Q., Cai, S., Wang, S., Zhao, B., Martin, R. V., Brauer, M., and Frostad, J.: Impacts of coal burning on ambient PM2.5 453 pollution in China, Atmos. Chem. Phys., 17(7), 4477, doi: 10.5194/acp-17-4477-2017, 2017.

454 Ma, Z., Liu, R., Liu, Y., and Bi, J.: Effects of air pollution control policies on PM 2.5 pollution improvement in China 455 from 2005 to 2017: a satellite-based perspective, Atmos. Chem. Phys., 19(10), 6861-6877, doi: 10.5194/acp-19-6861$4562019,2019$.

457 Nuno-Maganda, M. A. and Arias-Estrada, M. O.: Real-time FPGA-based architecture for bicubic interpolation: an 458 application for digital image scaling, In 2005 International Conference on Reconfigurable Computing and FPGAs 459 (ReConFig'05), IEEE., 8, 2005.

460 Olivier, R. and Hanqiang, C.: Nearest neighbor value interpolation, Int. J. Adv. Comput. Sci. Appl., 3(4), 25-30, 2012.

461 Sayer, A. M., Hsu, N. C., Lee, J., Kim, W. V., and Dutcher, S. T.: Validation, stability, and consistency of MODIS 462 Collection 6.1 and VIIRS Version 1 Deep Blue aerosol data over land, J. Geophys. Res. Atmos., 124(8), 4658-4688, doi: $46310.1029 / 2018 J D 029598,2019$.

464 Shen, H. and Li, T.: Progress of remote sensing mapping of atmospheric PM2.5, Acta Geodaetica et Cartographica Sinica., 465 48(12), 1624, doi: 10.11947/j.AGCS.2019.20190456, 2019.

466 Shtein, A., Kloog, I., Schwartz, J., Silibello, C., Michelozzi, P., Gariazzo, C., and Stafoggia, M.: Estimating daily PM2.5 467 and PM10 over Italy using an ensemble model, Environ. Sci. Technol., 54(1), 120-128, doi: 10.1021/acs.est.9b04279, 4682019.

469 Stafoggia, M., Bellander, T., Bucci, S., Davoli, M., De Hoogh, K., De'Donato, F., and Scortichini, M.: Estimation of daily 470 PM10 and PM2.5 concentrations in Italy, 2013-2015, using a spatiotemporal land-use random-forest model, Environ. Int., 
471 124, 170-179, doi: 10.1016/j.envint.2019.01.016, 2019.

472 Tao, J., Zhang, L., Cao, J., and Zhang, R.: A review of current knowledge concerning PM2.5 chemical composition, 473 aerosol optical properties and their relationships across China, Atmos. Chem. Phys., 17(15), 9485, doi: 10.5194/acp-17$4749485-2017,2017$

475 Theys, N., Smedt, I. D., Yu, H., Danckaert, T., Gent, J. V., Hörmann, C., and Pedergnana, M.: Sulfur dioxide retrievals 476 from TROPOMI onboard Sentinel-5 Precursor: algorithm theoretical basis, Atmos. Meas. Tech., 10(1), doi: 10.5194/amt477 10-119-2017, 2017.

478 Tucker, W. G.: An overview of PM2.5 sources and control strategies, Fuel Process. Technol., 65, 379-392, doi: 479 10.1016/S0378-3820(99)00105-8, 2000.

480 Van Donkelaar, A., Martin, R. V., Brauer, M., Kahn, R., Levy, R., Verduzco, C., and Villeneuve, P. J.: Global estimates of 481 ambient fine particulate matter concentrations from satellite-based aerosol optical depth: development and application, 482 Environ. Health Persp., 118(6), 847-855, doi: 10.1289/ehp.0901623, 2010.

483 Veefkind, J. P., Aben, I., McMullan, K., Förster, H., De Vries, J., Otter, G., and Van Weele, M.: TROPOMI on the ESA 484 Sentinel-5 Precursor: A GMES mission for global observations of the atmospheric composition for climate, air quality 485 and ozone layer applications, Remote Sens. Environ., 120, 70-83, doi: 10.1016/j.rse.2011.09.027, 2012.

486 Venkataraman, C., Brauer, M., Tibrewal, K., Sadavarte, P., Ma, Q., Cohen, A., and Millet, D. B.: Source influence on 487 emission pathways and ambient PM2.5 pollution over India (2015-2050), Atmos. Chem. Phys., 18(11), 8017-8017, doi: 488 10.5194/acp-2017-1114, 2018.

489 Wang, M., Sampson, P. D., Hu, J., Kleeman, M., Keller, J. P., Olives, C., and Kaufman, J. D.: Combining land-use 490 regression and chemical transport modeling in a spatiotemporal geostatistical model for ozone and PM2.5, Environ. Sci. 491 Technol., 50(10), 5111-5118, doi: 10.1021/acs.est.5b06001, 2016.

492 Wang, Y., Yuan, Q., Li, T., Shen, H., Zheng, L., and Zhang, L.: Large-scale MODIS AOD products recovery: Spatial493 temporal hybrid fusion considering aerosol variation mitigation, ISPRS J. Photogramm. Remote Sens., 157, 1-12, doi: 494 10.1016/j.isprsjprs.2019.08.017, 2019b.

495 Wang, Y., Yuan, Q., Li, T., Shen, H., Zheng, L., and Zhang, L.: Evaluation and comparison of MODIS Collection 6.1 496 aerosol optical depth against AERONET over regions in China with multifarious underlying surfaces, Atmos. Environ., 497 200, 280-301, doi: 10.1016/j.atmosenv.2018.12.023, 2019a.

498 Wang, Y., Li, W., Gao, W., Liu, Z., Tian, S., Shen, R., and Song, T.: Trends in particulate matter and its chemical 499 compositions in China from 2013-2017, Science China Earth Sciences., 62(12), 1857-1871, doi: 10.1007/s11430-018500 9373-1, 2019c. 
501 Wang, Y., Yuan, Q., Shen, H., Zheng, L., and Zhang, L.: Investigating multiple aerosol optical depth products from 502 MODIS and VIIRS over Asia: Evaluation, comparison, and merging, Atmos. Environ., 117548, doi: 503 10.1016/j.atmosenv.2020.117548, 2020.

504 Weagle, C. L., Snider, G., Li, C., van Donkelaar, A., Philip, S., Bissonnette, P., and Abboud, I.: Global sources of fine 505 particulate matter: interpretation of PM2.5 chemical composition observed by SPARTAN using a global chemical 506 transport model, Environ. Sci. Technol., 52(20), 11670-11681, doi: 10.1021/acs.est.8b01658, 2018.

507 Wei, J., Huang, W., Li, Z., Xue, W., Peng, Y., Sun, L., and Cribb, M.: Estimating 1-km-resolution PM2.5 concentrations 508 across China using the space-time random forest approach, Remote Sens. Environ., 231, 111221, doi: 509 10.1016/j.rse.2019.111221, 2019.

510 Xiao, Q., Wang, Y., Chang, H. H., Meng, X., Geng, G., Lyapustin, A., and Liu, Y.: Full-coverage high-resolution daily

511 PM2.5 estimation using MAIAC AOD in the Yangtze River Delta of China, Remote Sens. Environ., 199, 437-446, doi:

512 10.1016/j.rse.2017.07.023, 2017.

513 Yang, Q., Yuan, Q., Yue, L., Li, T., Shen, H., and Zhang, L.: Mapping PM2.5 concentration at a sub-km level resolution:

514 A dual-scale retrieval approach, ISPRS J. Photogramm. Remote Sens., 165, 140-151, doi: 10.1016/j.isprsjprs.2020.05.018, 515 2020a.

516 Yang, Q., Yuan, Q., Li, T., and Yue, L.: Mapping PM2.5 concentration at high resolution using a cascade random forest 517 based downscaling model: evaluation and application, J. Clean. Prod., 123887, doi: 10.1016/j.jclepro.2020.123887, 2020 b. 518 Yang, Q., Yuan, Q., Yue, L., Li, T., Shen, H., and Zhang, L.: The relationships between PM2.5 and aerosol optical depth 519 (AOD) in mainland China: About and behind the spatio-temporal variations, Environ. Pollut., 248, 526-535, doi: 520 10.1016/j.envpol.2019.02.071, 2019.

521 Yao, F., Wu, J., Li, W., and Peng, J.: A spatially structured adaptive two-stage model for retrieving ground-level PM2.5 522 concentrations from VIIRS AOD in China, ISPRS J. Photogramm. Remote Sens., 151, 263-276, doi: 523 10.1016/j.isprsjprs.2019.03.011, 2019.

524 You, W., Zang, Z., Zhang, L., Li, Z., Chen, D., and Zhang, G.: Estimating ground-level PM10 concentration in 525 northwestern China using geographically weighted regression based on satellite AOD combined with CALIPSO and 526 MODIS fire count, Remote Sens. Environ., 168, 276-285, doi: 10.1016/j.rse.2015.07.020, 2015.

527 Zhang, H. K. and Roy, D. P.: Using the $500 \mathrm{~m}$ MODIS land cover product to derive a consistent continental scale $30 \mathrm{~m}$ 528 Landsat land cover classification, Remote Sens. Environ., 197, 15-34, doi: 10.1016/j.rse.2017.05.024, 2017. 